\title{
A novel application of the transnasal gastroscope for endoscopic imaging of the appendiceal lumen
}

A 59-year-old man was admitted with a 1 -year history of recurrent diarrhea and abdominal pain. Colonoscopy performed the previous year showed multiple colonic ulcers, which were confirmed by pathology. Repeat colonoscopy demonstrated a sigmoid ulcer with stenosis that could not be traversed with an adult colonoscope.

The stenosis was successfully traversed with a transnasal gastroscope (GIF-XP260N, diameter $6 \mathrm{~mm}$, length 1050 mm; Olympus, Tokyo, Japan), which could reach the terminal ileum. Multiple ulcers were seen in the terminal ileum, ascending colon, transverse colon, and sigmoid, whereas the mucosa of the descending colon and rectum were normal. The transnasal gastroscope could also enter the lumen of the appendix, and showed that the appendiceal orifice was edematous ( $\triangleright$ Fig. 1 a). The appendix mucosa was smooth without erosion or ulceration ( $\triangleright$ Fig. $\mathbf{1}$ b). The entire appendiceal lumen could be visualized, including the tip of the appendix ( $\triangleright$ Fig. $1 \mathbf{c}$ ). The interior folds of the appendix were also clearly seen by the transnasal gastroscope ( $\triangleright$ Fig. $1 \mathrm{~d}, \triangleright$ Video 1 ).

Endoscopic imaging of the appendix has been described by others using SpyGlass (Boston Scientific, Marlborough, Massachusetts, USA) [1,2]. However, SpyGlass is expensive, requires a colonoscope, and provides poorer image quality. This is the first report of successful use of a transnasal gastroscope to examine the entire appendiceal lumen and capture high quality images and a good video. We suggest that a transnasal gastroscope could be used when examination of the appendix is required. The transnasal gastroscope could also be useful in the future for some endoscopic surgery procedures such as endoscopic retrograde appendicitis therapy [3].

Endoscopy_UCTN_Code_CCL_1AD_2AJ

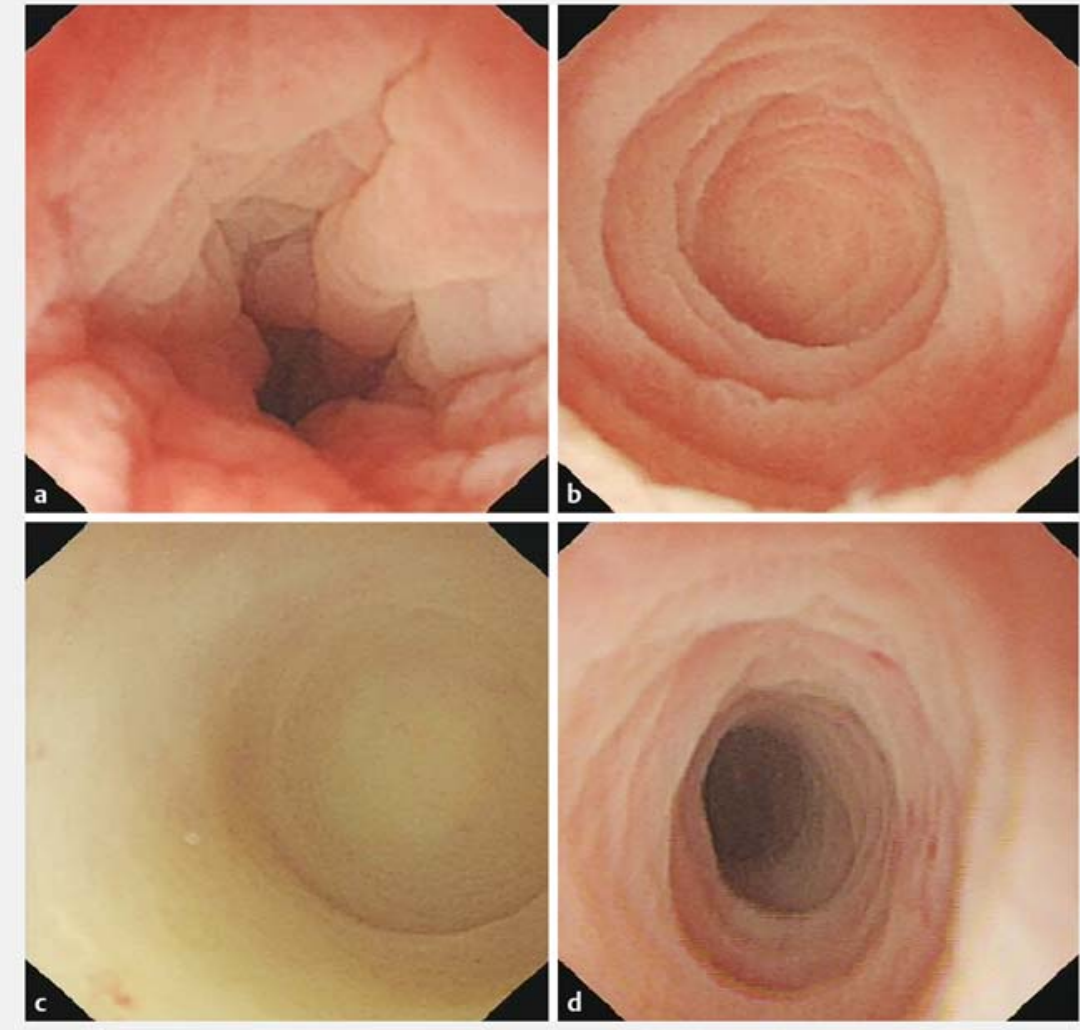

Fig. 1 Endoscopic images of the appendix using a transnasal gastroscope. a Edema of the appendiceal orifice. $\mathbf{b}$ Mucosa of the appendiceal lumen. $\mathbf{c}$ Tip of the appendix. $\mathbf{d}$ Interior fold of the appendix.

\section{Acknowledgments}

The authors are grateful to T.-C. He, MD, PhD, and Marc Bissonnette, MD, of the University of Chicago Medical Center for reading and critiquing the manuscript. The authors also thank Dr. Satish Chandra Yadav of Grande International Hospital Kathmandu Nepal for revising the paper.

\section{Competing interests}

The authors declare that they have no conflict of interest.
The authors

Binglan Zhang, Xuchun Zhou, Fang Tan, Bingqiang Zhang

Department of Gastroenterology, First Affiliated Hospital, Chongqing Medical University,

Chongqing, China

\section{Corresponding author}

\section{Bingqiang Zhang, MD}

Department of Gastroenterology, First Affiliated Hospital, Chongqing Medical University, 1 Youyi Road, Ruan jiagang, Yuzhong District, Chongqing, 400016, China zhbingqiang@163.com 


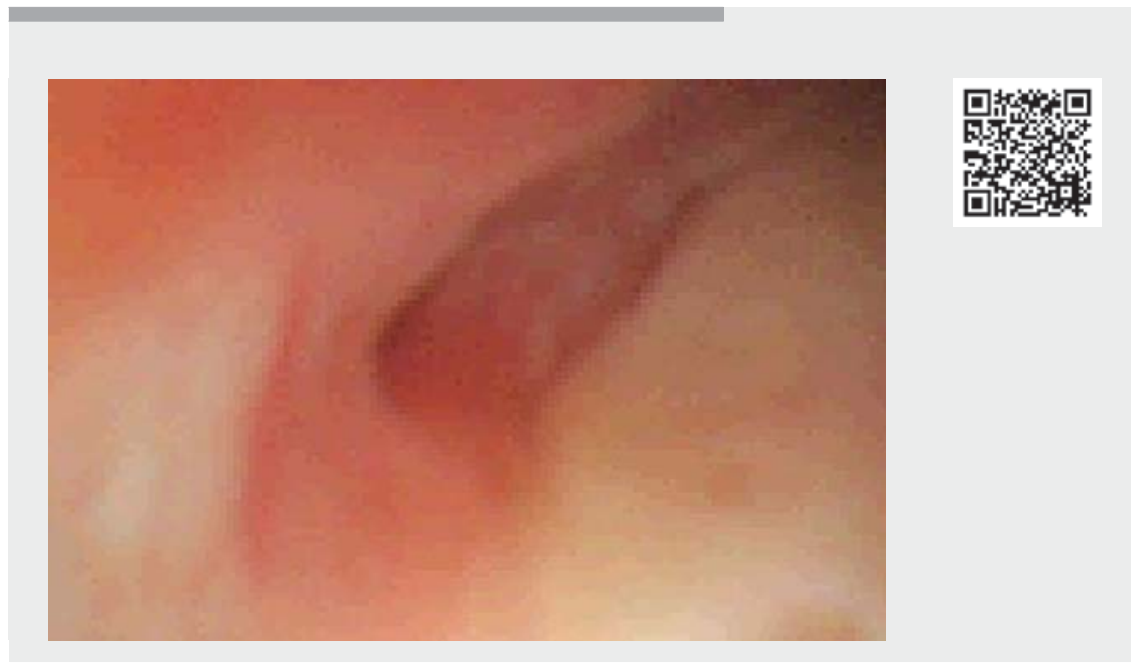

$\checkmark$ Video 1 A novel application of the transnasal gastroscope for endoscopic imaging of the appendiceal lumen.

\section{References}

[1] Ferlitsch A, Puspok A, Gasche C. Detection of appendix pathology by a novel endoscopic imaging procedure. Gastrointest Endos 2012; 75: AB173

[2] Ferlitsch A, Puespoek A, Gasche C. Endoscopic imaging of the vermiform appendix
Bibliography

Endoscopy 2022; 54: E462-E463

DOI 10.1055/a-1625-4810

ISSN 0013-726X

published online 27.9.2021

(C) 2021. Thieme. All rights reserved.

Georg Thieme Verlag KG, Rüdigerstraße 14, 70469 Stuttgart, Germany

\section{ENDOSCOPY E-VIDEOS}

https://eref.thieme.de/e-videos

回的 Endoscopy E-Videos is an open access online section, 回和: reporting on interesting cases and new techniques in gastroenterological endoscopy. All papers include a high quality video and all contributions are freely accessible online. Processing charges apply (currently EUR 375), discounts and wavers acc. to HINARI are available. 1156-1160

[3] Kong L], Zhao LP, Liu BR et al. Su1364 Spy Glass's application in ERAT for the management of acute appendicitis. Gastrointest Endos 2019; 89: AB347

This section has its own submission website at

https://mc.manuscriptcentral.com/e-videos 